This paper is a postprint of a paper submitted to and accepted for publication in IET Intelligent Transport Systems and is subject to Institution of Engineering and Technology Copyright. The copy of record is available at IET Digital Library.

Official URL: http://dx.doi.org/10.1049/iet-its.2009.0046

The full citation for this paper is:

Hounsell, N.B., Shrestha, B.P., Piao, J. and McDonald, M. (2009) Review of urban traffic management and the impacts of new vehicle technologies. Institution of Engineering \& Technology, Intelligent Transport Systems, 3, (4), 419-428. (doi:10.1049/iet-its.2009.0046) 


\title{
Review of Urban Traffic Management and the Impacts of New Vehicle Technologies
}

\author{
N.B. Hounsell, B.P. Shrestha, J. Piao and M. McDonald \\ Transportation Research Group \\ School of Civil Engineering and the Environment \\ University of Southampton \\ Southampton, United Kingdom \\ Email: N.B.Hounsell@soton.ac.uk \\ Tel: +44 (0) 2380593705; Fax +44(0)2380593152
}

\begin{abstract}
Traffic congestion is a growing problem in most urban areas across the world. In recent years, the problem has often been tackled by management of existing capacity rather than the traditional concept of more road building. This requires efficient traffic management tools and has led to widespread implementation of advanced traffic control systems integrated within a wider Urban Traffic Management (UTM) environment. UTM systems collect data from various sources, process and manage the data and use this information to implement various measures to manage traffic.
\end{abstract}

Whilst infrastructure-based UTM systems continue to develop, there is now also a rapid market-driven development of vehicle technologies and in-vehicle driver support systems. Driver information and satellite navigation systems are two examples already in widespread use, whilst other applications under research and development include Intelligent Speed Adaptation (ISA), Adaptive Cruise Control (ACC) and various other safety-related applications.

This paper will firstly present state-of-the-art reviews of UTM and in-vehicle systems. It will then discuss the potential impacts of new in-vehicle systems on UTM and opportunities for beneficial co-operation between the two. The research described in the paper has been undertaken within a collaborative project FUTURES, funded by the Engineering and Physical Sciences Research Council (EPSRC).

\section{Background}

Traffic congestion is a growing problem in the most urban areas across the world. In recent years, the problem has often been tackled by management of existing capacity rather than the traditional concept of more road building. This requires efficient traffic management tools and has led to widespread implementation of advanced traffic control systems such as SCOOT, with its many functions for urban traffic management [1]. Some cities have expanded this capability into integrated systems for traveller information and traffic management, such as ROMANSE in Southampton [2]. This can include implementation of integrated Urban Traffic Management and Control (UTMC) applications [3] such as traffic and parking information, bus information/priority systems and automatic incident detection. In each case, applications can be chosen to match policy objectives, so that in London, for example, greater emphasis has been on congestion charging, automatic enforcement systems and public transport improvements.

Given the continuing development of new technologies for detection, communications, data fusion, etc there will be a clear need for continuing research into how these technologies can be best deployed for urban traffic management. However, even greater market-driven development is likely to be seen in the coming years concerning vehicles and vehicle 
technologies, which could have a significant impact on driver behaviour and vehicle performance in urban areas. We are already seeing a range of smaller vehicles and different propulsion/fuel options in the market place, more suited to congested, low speed urban environments. In addition, many Advanced Driver Assistance Systems (ADAS) are being developed such as adaptive cruise control and Stop\&Go [4], [5]). Applications of such new vehicle systems have great potential to impact not only on safety, but also on a range of traffic management systems, including 'basic' features such as signalised and non-signalised junction operations, pedestrian facilities and road layouts/markings, as well as more advanced optimisation functions.

This paper reviews the current state-of-the-art of the various UTM and vehicle technologies mainly in the UK context and discusses the potential impacts of new vehicle technologies on UTM and opportunities they provide.

\section{Introduction to UTM}

Urban Traffic Management (UTM) aims to implement and integrate a range of technologysupported applications to achieve the common goal of efficient management of the urban traffic and transport system. A UTM system collects data from various sources, processes and manages the data in a common database and uses this real-time information to implement various measures to manage traffic. These measures include Urban Traffic Control (UTC), Variable Message Signs (VMS), passenger information systems and so on. A conceptual diagram of UTM is given in Figure 1

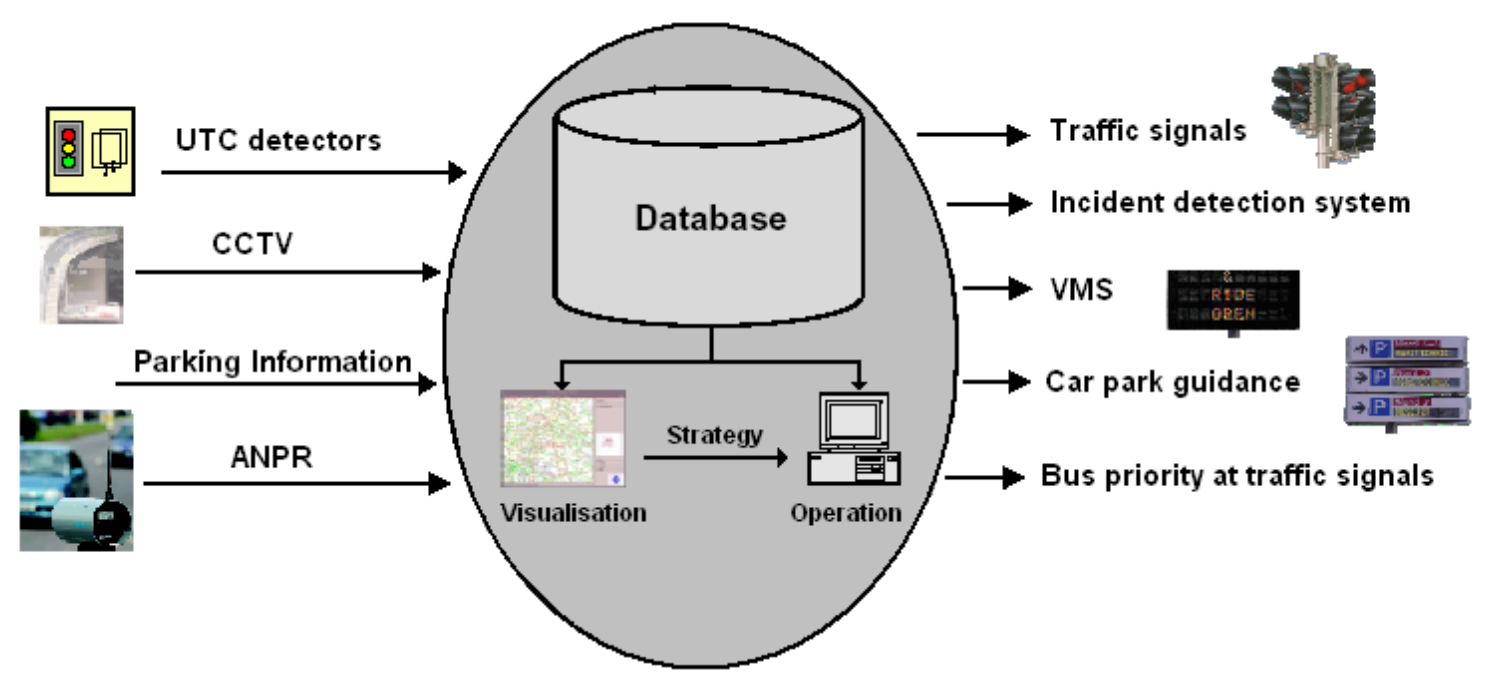

Figure 1: Conceptual diagram of Urban Traffic Management systems

A key initiative in this area in the UK has been the Urban Traffic Management and Control (UTMC) research and development programme, launched by the Department for Transport (DfT) in 1997 [6]. The aim of this programme was to provide the tools to support efficient and effective network management. Under this programme, the UTMC concept has been developed to create modular systems which are capable of expansion and interoperability with other systems. A number of research projects were undertaken within this initiative to establish and validate an approach based on modular systems and open standards. Demonstration projects have been undertaken in Preston, Reading, Stratford-upon-Avon and York as a part of the programme. After the completion of this demonstration phase, the UTMC initiative now continues to be active as the UTMC Development Group - UDG [3]. 
With the development of new technologies, there are various methods of collecting data; communicating them to the control centre; and using the data for traffic management applications available for UTMC. For example, recent data collection technology such as Automatic Number Plate Recognition ANPR) has made it possible to recognise individual vehicles more easily while General Packet Radio Service (GPRS) has allowed communication with remote sites.

The UTM concept shown in Figure 1 can be classified into 4 distinct parts, each supported by different technology:

- data collection technologies

- communication technologies

- common database; and

- UTM applications.

The current state-of-the-art of these 4 distinct parts of UTM systems are discussed in the next section.

\section{Current state-of-the art of UTM technologies}

\subsection{Data collection technologies}

Comprehensive and accurate data is the primary requirement of a UTM system. Various technologies have been enhanced/developed in recent years to improve this data collection quantity and quality though two main categories can be identified: infrastructure-based technologies, where field infrastructure is needed; and vehicle-based technologies in which a vehicle needs to be equipped (field infrastructure is not needed). At present, data collection for UTM applications is achieved mainly by infrastructure based data collection systems such as inductive loops, beacons, CCTV (Closed Circuit Television) and ANPR (Automatic Number Plate Recognition), though the scope for vehicle-based systems is increasing rapidly.

\subsubsection{Infrastructure based technologies}

Inductive loops embedded in the road surface remain a key technology for traffic detection. An inductive loop is a simple and reliable way to detect the movement of vehicles over a road surface and is extensively used in traffic responsive traffic signal systems such as SCOOT [7] to collect traffic data to optimise signal timings accordingly. Such loops can provide data on traffic density, flows and speeds for offline analysis (e.g. Automatic SCOOT traffic information database, ASTRID [8]) as well as providing a key input to on-line traffic models which predict queues, delays, etc. Beacon-based technology detects a vehicle by a "Beacon" positioned at a known location employing various technologies including microwave, infra-red and Dedicated Short Range Communication (DSRC) beacons. Beacon-based technology has been used for various UTM applications such as bus priority at traffic signals [9], Real Time Passenger Information (RTPI) and road user charging. CCTV is commonly used to monitor traffic operations at key locations in urban networks, such as major junctions, road bottlenecks, tunnels etc. CCTV pictures can be used as a basis for altering traffic control strategies, for confirmation of incidents, and to record conditions or events over a period of time. CCTV is the main means of receiving precise visual information relating to the road network at present and no other technology is likely to replace it in the near future. ANPR is a camera based technology that records registration numbers of individual vehicles. This system can be used not only for traffic enforcement purposes but also to provide journey time measurements. These can be used for various purposes such as journey time monitoring, incident detection and Origin-Destination (O-D) surveys. The use of ANPR for journey time monitoring on strategic routes has grown in recent years (e.g. ROMANSE (http://southampton.romanse.org.uk/) and Stratford-upon-Avon [10]). 


\subsubsection{In-vehicle technologies}

One of the main vehicle-based data collection systems is based on the Global Positioning System (GPS). This is the worldwide form of satellite navigation ('Sat-nav') systems developed and operated by the United States military, which is used increasingly in private cars and commercial fleets. From the UTM point of view at present, relevant use of GPS is more on public transport fleets to locate/detect buses for various purposes such as bus fleet management, real time passenger information and bus priority at traffic signals. Nevertheless, its future potential for other applications such as flexible road pricing has been identified (e.g. [11], [12]). Other emerging vehicle-based technologies for collecting traffic data include: cell-based technology and floating car technology. Cell-based technology can be used to predict the state of a traffic network using location and movement data from mobile phones within vehicles, which can be collected at low cost with sufficient accuracy for some applications. For example, a trial carried out in Europe [13] showed that the data can be used to forecast network state with acceptable accuracy. Floating car technology collects data using a sample of vehicles moving in the network to assess the state of the traffic. Discussion of these applications and their potential impacts on UTM systems is given in Section 5.

\subsection{Communication technologies}

The rapid development in the field of communications has resulted in numerous technologies being available and used in UTM systems. These technologies vary in terms of price, capacity and method of working. These range from well established systems based on telephone cables ('land lines') to mobile-based technology such as General Packet Radio Service (GPRS) which was made widespread in the Real Time passenger Information (RTPI) system in the UK under the "Transport Direct" initiative [14]. Being mobile technology, it allows communication with remote sites such as variable message signs and car park counters. The Asymmetric Digital Subscriber Line (ADSL) is another technology very useful for a communications link where the data flow is mainly in one direction (e.g. transmission of CCTV images to the control centre). A recent addition to this area is wireless broadband to communicate, for example, between buses, the control centre and real time passenger information signs.

\subsection{Common database}

Recent UTM systems use common databases to manage the various traffic information inputs and build the 'best' picture of the network state given the data available, as a basis for traffic management. The use of a common database enables easier access to the overall traffic network information. One such example is Siemens' Comet system [15] used in cities like Southampton and Reading. It makes it possible to implement various traffic management applications such as VMS and UTC systems in an integrated way. For example, in Stratfordupon-Avon, journey time information is provided to the traveller via VMS using the information from ANPR cameras and data from UTC within the common database [9]. Glasgow, York and Sheffield are among a growing number of UK cities implementing a common database system. A future direction of the use of common databases is towards the integration of various traffic management measures to respond more effectively to traffic incidents. For example, after a major traffic incident, traffic management measures such as traveller information, display of VMS messages and UTC timings could act together to recommend and support specific diversion routes.

\subsection{UTM Applications}

Some of the key urban traffic management applications currently in use within UTM systems, are described in the following paragraphs. 


\subsubsection{Urban Traffic Control (UTC)}

Urban Traffic Control (UTC) is usually the main traffic management and control tool among the UTM applications. The aim of UTC has traditionally been to implement signal timings which minimise the total vehicular delay in the network. In the case of SCOOT, which is the most common UTC system used in the UK, these timings are responsive to traffic variations in the network. Over the last decade or so, the focus has been increasingly to prioritise particular modes of transport (e.g. buses, cyclists and pedestrians) and to consider congestion, traffic emissions and other performance criteria in UTM strategies (e.g. [16]). Bus priority at traffic signals is one such area where more innovative strategies have been developed. Early systems started with the use of bus inductive loop detectors, then progressed to beacon-based bus detection and now have been largely overtaken by satellitebased systems (e.g. GPS). In recent years, the bus priority facility is a part of an overall system based on Automatic Vehicle Location (AVL) implemented for various public transport applications (e.g. iBUS system in London [17]).

\subsubsection{Fault and incident detection systems}

Fault and incident detection systems are now readily available within UTC. Facilities available within SCOOT such as ASTRID (Automatic Scoot TRaffic Information Database) and INGRID (INteGRated Incident Detection) [8] help in detecting faulty SCOOT loops and give an early warning of traffic incidents. Such systems are currently based on the traffic flows and occupancy from the loop detectors which may be supplemented or replaced with more accurate data from Automatic Number Plate Recognition (ANPR) cameras in due course.

\subsubsection{Variable Message Signs [VMS]}

Variable Message Signs [VMS] are widely used in traffic networks to give current traffic information at strategic places. The aim of using VMS is to provide drivers with advisory information at the roadside, relating to situations ahead or in the immediate vicinity. In some places, VMS signs are also used to give more informed choice to the drivers. An example in Reading is where VMS is used to give car park information with alternative choices so that a driver can be directed towards the appropriate place quickly [10]. More generally, Parking Guidance and Information systems (PGI) are now implemented in many cities across the UK. These systems monitor the car park availability and inform drivers of car park location and spaces available by means of car park information signs. Figure 2 shows examples of variable message sign and parking guidance information used in Southampton. In recent years, car park information is also made available on the internet, therefore giving drivers pre-trip information also. 


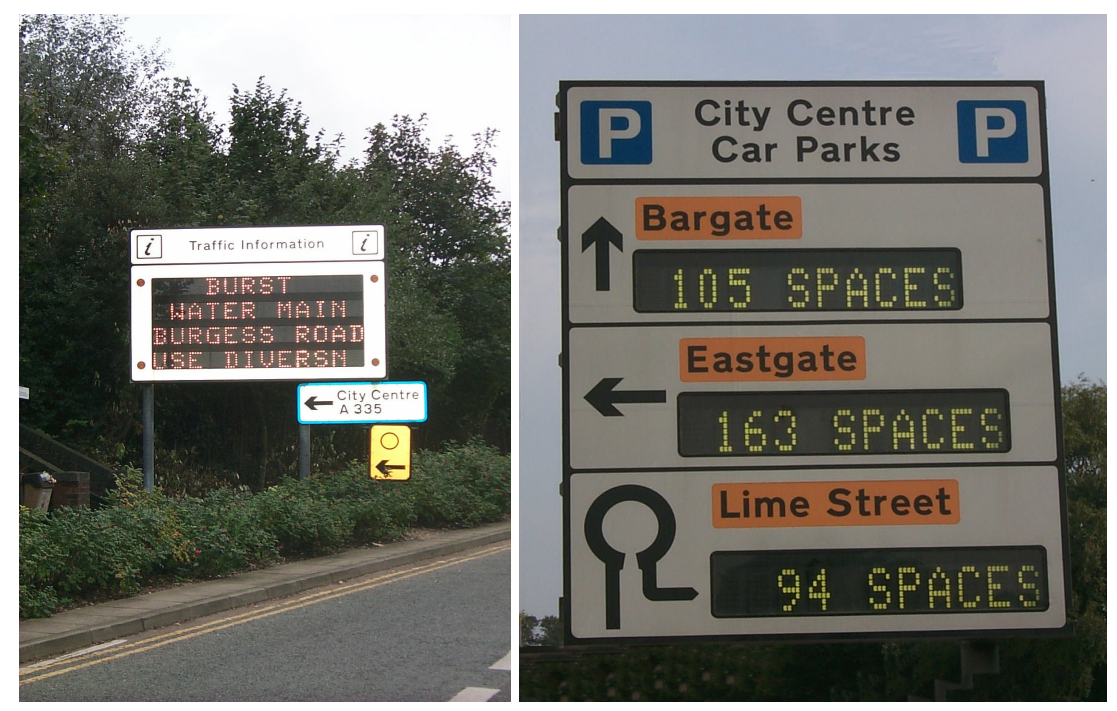

Figure 2: Variable message sign and Parking guidance information in Southampton

\section{$4 \quad$ New in-vehicle applications/technologies}

This section summarises some of the new applications/technologies being used within vehicles to improved efficiency, comfort and safety.

\subsection{In-vehicle information and navigation systems}

Various systems have emerged in recent years to give drivers real time traffic information and/or to offer navigation and route guidance.

\subsubsection{In-vehicle traffic information}

In-vehicle information systems can be used to warn drivers of hazards on their routes including accidents, adverse weather or road surface conditions, roadworks, and traffic jams. The main objective of such services is to increase driver awareness and alertness of the events. An example is RDS-TMC (radio data systems-traffic message channel) which broadcasts traffic congestion related information. Such informationcan help drivers to make better travel decisions that improve network efficiency and reduce fuel consumption and emissions. However, better knowledge of the traffic situation may courage some drivers to start trip making and thus putting more pressure on UTM. Currently a new generation of invehicle information systems are being developed which are based on two-way wireless communications. The systems are not only able to broadcast traffic information, but also have the capability to provide personalised information service (with vehicle location being taken into account). Several research projects are ongoing in this area including the EC funded COOPERS [18] and CVIS [19] projects, and American VII projects [20].

\subsubsection{In-vehicle navigation systems}

Navigation systems provide real-time information on vehicle location and, increasingly, route guidance for drivers to reach their selected destinations on an 'optimum' route. Navigation systems have an automatic vehicle location function (e.g. currently mainly using GPS technology) that locates the vehicle within the network, a route planning function that assigns a path before or during a trip according to pre-selected criteria or preferences, and a route guidance function which directs the driver along the planned route. This helps, in general, taking an optimum route reducing wasted mileage and improving network efficiency despite few reported incidences of navigating vehicles into unsuitable roads. Falling retail costs in this market have led to an ever-increasing and rapid proliferation of 'sat-nav' sytems in the 
UK. In 2006 over £305 million was spent on such systems by UK drivers and this represented a five-fold increase on 2003 [21].

Most current navigation is based on static information of road conditions. The quality of such route guidance may be affected by abnormal traffic conditions such as accidents and other incidents. Improved routing then requires dynamic route guidance (DRG) with up-to-date traffic information obtained, processed and delivered to the vehicle. An early prototype system of such in-car navigation, Siemens' Ali-Scout system, was trialled in West Berlin's LISB deployment [22] and in Michigan's FAST-TRAC program [23]. The systems were based on beacons installed at key locations on the network to transmit data to the in-vehicle units and receive from vehicles information. However, these systems and their infrastructure requirements were not sufficiently cost effective to penetrate the mass market. An option available in the UK market is where RDS-TMC with in-vehicle navigation systems [24]. In this option, real time traffic condition information provided via RDS-TMC is used to facilitate dynamic re-routing using in-vehicle navigation systems.

\subsection{Advanced driver assistance systems (ADAS)}

ADAS systems aim to support drivers by either providing a warning to reduce risk exposure, or automating some of the control tasks to relieve a driver from manual control of a vehicle. From an operational point of view, such systems are a clear departure from a century of automobile development where drivers have had control of all driving tasks at all times. ADAS could replace some of the human driver decisions and actions with precise machine tasks, making it possible to eliminate many of the driver errors which could lead to accidents, and to achieve more regulated and smooth vehicle control with increased capacity and associated energy and environmental benefits. Examples of ADAS systems which have the potential to impact on traffic management are summarised below.

\subsubsection{Cruise control assistance systems}

Adaptive Cruise Control (ACC) aims at relieving a driver from manually adjusting his/her speed to achieve a safe cruise control. When driving in free traffic, the system holds a preset speed, like a conventional cruise control system, whilst when following another vehicle, the system automatically maintains a desired time-gap from the proceeding vehicle [25]. The systems have the potential to reduce accidents due to close following and hence reducing congestion and additional fuel consumption as a result. Unlike ACC, which is mainly developed for highway operations, Stop\&Go systems aim to support cruise control at low speed driving with the capability of automatic start and/or stop [26]. Driving with Stop\&Go can relieve a driver from frequent accelerations and brake operations and increase driver comfort in congested traffic. Apart from driving comfort, Stop\&Go could improve safety with its short reaction time [26]. To operate in urban traffic conditions, the system has to react not only to the vehicle in front, but also to other road users (e.g. pedestrians, cyclists), therefore the detection and control requirements are much more stringent than those for ACC. These systems have the potential to improve safety in addition to driving comfort. However, the change (increase/decrease) in the traffic capacity as a result of such system depends on the headway settings used.

\subsubsection{Intersection collision warning and avoidance systems}

Intersection collision warning and avoidance systems aim at detecting impending collisions at intersections and alerting the drivers of at-risk vehicles to potentially hazardous situations [27]. Both vehicle-based and infrastructure-based sensors are used (the latter identifying the intersection state and approaching vehicles) which intercommunicate typically through the use of Dedicated Short Range Communications (DSRC). Although some early versions of this functionality were based solely on vehicle or infrastructure support, almost all recent research has focused on cooperative solutions, generically termed Cooperative Intersection Collision Avoidance Systems (CICAS) [28]. For realising CICAS functions, precise vehicle 
positioning is required in order to assess collision risks between the host vehicle and vehicles approaching from other arms of the intersection. In addition, reliable and low latency communication is crucial for ensuring timely data exchanges between roadside infrastructure and vehicles (e.g. speed, position etc). Currently, most of these systems are still at the prototype stage as the system is very expensive due to the stringent detection and processing requirements [29].

\subsubsection{Intelligent speed adaptation (ISA) systems}

Intelligent Speed Adaptation (ISA) systems are developed to help drivers to avoid speeding. ISA can take various forms, for example providing warning (e.g. visual, audio or vibration), or limiting the speed to the official limit with/without possibility of override. A field study [30] found that ISA had a significant speed suppressing effects on road with speed limits ranging $30-70 \mathrm{~km} / \mathrm{h}$. The ISA concept is under active R\&D in Europe: Following small field trials in 1996-1997, more extensive road trials were carried out in four Swedish cities in 1999-2001 with 4000 equipped vehicles [31]. Since then much research has been conducted at international or national levels including the EC-funded projects MASTER (1996-1998), DUMAS (1998-2001), STARDUST (2001-2004) and PROSPER (2002-2005). A large amount of ISA field operational tests have been conducted and it is expected that systems will be implemented within new vehicles in the next 10 years.

\subsection{Floating car data collection}

Many new in-vehicle systems are supported by technologies which can also be used to provide data for other purposes. For example, vehicles equipped for Satellite Navigation (Sat-Nav) can also be used to provide route-specific journey time data, also known as Floating Car Data (FCD). Collecting traffic or other relevant information using 'Probe vehicles' while travelling within the road network is a cost effective means compared to the installation of fixed instruments at various locations [24]. The process of FCD data collection includes collecting data automatically from individual vehicles, aggregating the data at a processing centre and extracting useful information (e.g. location and status of traffic jams). Currently, FCD data is mainly used for monitoring traffic, journey time estimation and incident detection. Extended Floating Car Data (XFCD) is a concept where on-board sensor results relating to the road environment such as road surface conditions and weather conditions are transmitted to following vehicles or to the UTM control centres for improving incident detection and/or improving information services [32]. It is to be noted that the data collected from such a method could be used for traffic management strategies over a wide area but could not be used for strategies targeting individual vehicles (e.g. priority to a bus at traffic signals).

\section{Impacts of new vehicle technologies on UTM systems}

The previous sections have identified a range of circumstances where new in-vehicle technologies and applications could impact significantly on UTM. A summary of these impacts is shown in Table 1. 
Table 1: Summary of impacts of vehicle technologies on UTM

\begin{tabular}{|c|c|c|}
\hline \multirow{2}{*}{ Vehicle technology } & \multicolumn{2}{|c|}{ Effect on Urban Traffic Management } \\
\hline & Positive & Negative \\
\hline \multicolumn{3}{|c|}{ In-vehicle information systems } \\
\hline $\begin{array}{l}\text { In-vehicle information } \\
\text { system }\end{array}$ & $\begin{array}{l}\text { Better travel decisions; improved } \\
\text { network efficiency; reduced fuel } \\
\text { consumption and emissions }\end{array}$ & $\begin{array}{l}\text { - More pressure on UTM } \\
\text { with potential increase in } \\
\text { trip making }\end{array}$ \\
\hline $\begin{array}{l}\text { In-vehicle } \\
\text { navigation/guidance } \\
\text { system }\end{array}$ & $\begin{array}{l}\text { Reduced wasted mileage, } \\
\text { improved network efficiency and } \\
\text { potential reduction of UTM } \\
\text { infrastructure such as traffic signs } \\
\text { and VMS }\end{array}$ & $\begin{array}{l}\text { - Potential diversion onto } \\
\text { inappropriate links and } \\
\text { Potential contradiction to } \\
\text { UTM strategy and static } \\
\text { signs or VMS }\end{array}$ \\
\hline
\end{tabular}

Advanced driver assistance systems

$\begin{array}{ll}\text { Cruise control } & \text { - ACC could reduce headways and } \\ \text { assistance systems } & \text { increase efficiency (mainly in } \\ & \text { highways) [25] } \\ \text { - Stop\&Go could increase capacity } & \text { at signal with shorter reaction } \\ & \text { delays and reduce emissions with } \\ & \text { smoother vehicle movements [26] }\end{array}$

\begin{tabular}{|c|c|c|}
\hline $\begin{array}{l}\text { Intersection collision } \\
\text { avoidance }\end{array}$ & $\begin{array}{l}\text { - Improved traffic safety and } \\
\text { reduced accident induced delays } \\
\text { [27] } \\
\text { - Potential improvement in junction } \\
\text { efficiency with shorter intergreen } \\
\text { times }\end{array}$ & $\begin{array}{l}\text { - Very costly due to } \\
\text { stringent detection and } \\
\text { processing requirements } \\
\text { for practical applications. } \\
\text { - May never be } 100 \% \\
\text { effective }\end{array}$ \\
\hline $\begin{array}{l}\text { Intelligent Speed } \\
\text { Adaption (ISA) }\end{array}$ & $\begin{array}{l}\text { - Traffic speeds better matched to } \\
\text { road function and speed limit [30] } \\
\text { - Potential reduction in accidents } \\
\text { and severity } \\
\text { - Smoother traffic, improved } \\
\text { efficiency, less pollution } \\
\end{array}$ & $\begin{array}{l}\text { - Different forms of ISA } \\
\text { and/or different rates of } \\
\text { implementation could } \\
\text { cause unwanted variability } \\
\text { in performance }\end{array}$ \\
\hline \multicolumn{3}{|l|}{ Other systems } \\
\hline $\begin{array}{l}\text { Floating car data } \\
\text { (probe vehicles) }\end{array}$ & $\begin{array}{l}\text { - Flexible method of collecting } \\
\text { information [24] for potential } \\
\text { traffic management use }\end{array}$ & $\begin{array}{l}\text { - Potential issues of privacy } \\
\text { - Not suitable for individual } \\
\text { vehicle based strategy }\end{array}$ \\
\hline
\end{tabular}

Table 1 shows that new vehicle technologies and applications can have a positive effect on UTM systems, in general. They can help to improve the efficiency of the traffic network, reduce accidents and help to reduce emissions. However, some negative impacts or difficulties have been identified, particularly concerning system complexity/cost, inappropriate autonomous operations and the potential to increase private traffic trips.

Among the applications shown in Table 1, in-vehicle navigation is in widespread use and this is leading to much wider availability of 'floating car' data. These are probably the key current examples where in-vehicle applications/data can have a significant impact on UTM. They are therefore taken as examples to discuss in more detail in the following sections. 


\subsection{In-Vehicle Navigation/Route Guidance system and UTM}

Of the vehicle-based ITS systems, navigation systems are the only group to date that have reached large scale market penetration. The use of in-vehicle satellite navigation systems represents an increasingly significant issue for UTMC and this is likely to become more prevalent in the coming years as the use of 'SatNavs' increases. In the UK FUTURES project [33], the following issues have been identified regarding applications of navigation systems:

A concern with the current navigation systems is that they may advise a vehicle onto unsuitable roads, for example a route containing many small/narrow roads, junctions, and across residential areas. Driving on such a route could increase safety risks and may lead to congestion and delays and hence working against the aim of the UTM applications. Other types of 'system failure' could result from (i) the map stored in the vehicle not being updated regularly, so that significant changes to the real road network have occurred unknown to the system, or (ii) the navigation system fails to locate the vehicle accurately enough on the network, so the driver misses a crucial turn. Currently there are few post-market evaluation results to show the extent of such problems in driver's daily use of the systems [29], though it may be expected that such problems will reduce as initial errors are ironed out.

Another concern for traffic managers is the potential for conflicts between in-vehicle and roadside guidance. Roadside guidance signs, e.g. VMS, or other temporary signs, are often used in situations when an incident occurs (e.g. an accident, unplanned roadworks etc), for guiding drivers to avoid the "problem" road sections. With mostly autonomous navigation systems, real time traffic conditions are not able to be taken into account, which may result in the route advised by the navigation systems being in conflict with roadside guidance (e.g. guided to a route with temporary roadworks). This can also arise in normal traffic conditions with contradictions between in-vehicle advice and static roadside signing. Such conflicts may cause confusion among users and could lead to mistrust in one or both information sources. To avoid such conflicts, real time traffic information set by the Highway Authority would have to be integrated into in-vehicle route guidance.

With reducing prices, navigation systems are installed in more and more vehicles with a possibility of becoming a standard component of new vehicles in the near future. At present, navigation systems are developed independently by different companies using their chosen routing algorithm. There is a concern that users receiving similar advice may lead to shifting of congestion from one part of the network to another [34]. From the UTM point of view, it is necessary to investigate the potential impacts of "similar advice" and find measures to avoid the situation of congestion being shifted over a network. To avoid this situation in high penetration levels, 'multi-routing' may be needed between O-D pairs to achieve a 'system optimum' routeing pattern. However, this can conflict with the objectives of SatNav users seeking their own 'User optimum' route

Providing real time traffic information is crucial for increasing the effectiveness of route guidance. A combination of RDS-TMC and navigation has shown the potential for real time traffic information to improve the navigation service [24]. Such a system needing no field infrastructure is much more flexible that the system trialled in Berlin earlier [22]. Again, with the rapid advancement of wireless communications, it is possible that future navigation systems may be supported by two way communication between vehicles and traffic control centres. On the one hand, the communication can be used to provide real time traffic information to improve navigation performance. On the other hand, the feedback from vehicles can be used for traffic control centres to understand how drivers respond to navigation and as a means for traffic monitoring and incident detection. 


\subsection{Data from probe vehicles use for UTM application}

Probe vehicles can be used as tool for traffic data collection (e.g. journey time, speed, and location) while travelling within the road network. Apart from providing traffic data, some FCD vehicles could in the future also be used for collecting other information, for example weather and road conditions, thus forming an Extended Floating Car Data System (XFCD). With XFCD, vehicles equipped with on-board weather/road condition sensors could transmit information directly from one car to other cars or to traffic control/information centres. It is expected that the additional information from XFCD will contribute to improving journey time estimation and incident detection. The research is still at an early stage and car makers have yet to agree on a common standard for XFCD data [35]. Although FCD has great potential to generate high quality traffic information for UTM, one of the main barriers for preventing its rapid development is the number of different organisations in the traffic information market, covering a portion of the network. FCD has not yet developed to mass market implementation, because of barriers such as the communication cost, the difficulty to "measure" the quality and because FCD is not a service by itself (not visible to the driver as such) [36].

\subsection{Cooperative systems for supporting UTM}

The previous sections have outlined a range of situations where co-operation between invehicle and traffic management centre would be beneficial. This has been recognised by the EC in particular, where a substantial investment has been made in supporting R\&D projects on co-operative systems. Examples include COOPERS [18] and CVIS [19] projects. This is a significant activity but most potential applications are currently in their early stages of research, and beyond the scope of this paper for inclusion.

\section{Concluding remarks}

In recent years, the implementation of UTM systems has grown rapidly to tackle growing traffic congestion. This has led to the continuous development of more technologies for data collection, communication and traffic management applications with the goal of improving traffic efficiency, safety and or environmental 'performance'. There are now also many new vehicle technologies being developed which may have impacts on urban traffic management directly or indirectly. Among them, in-vehicle information systems and satellite navigation systems in particular, are the only vehicle applications to date that have reached large scale applications with improved affordability. These can be very useful in guiding a driver to reach his/her destination in normal traffic conditions on a reasonably optimum route. However, there are some concerns with these first generation systems, such as: (i) the capability of basic navigation systems without real time traffic information to provide effective guidance in incident conditions and (ii) drivers sometimes being advised to use unsuitable roads. There is a clear need here for co-operation between system providers and traffic management authorities, as a first step towards achieving effective integrated systems.

Other in-vehicle applications such as ADAS systems aim to support drivers by either providing warning to reduce risk exposure, or automating some of the control tasks to relieve a driver from manual control of a vehicle. Currently some warning mode ADAS systems have become available on the market such as forward collision warning that can reduce the number of accidents, related traffic congestion and negative environmental impacts. Application of probe vehicles has been seen in some pilot trials for collecting journey time information which can be useful for network state monitoring, travel planning and for rerouting, particularly in incident conditions. However, current feedback remains, at present, mainly to the service provider rather than to the traffic management authority as well, so that potential network benefits are not yet being realised. 
This paper has demonstrated that newer vehicle technologies can have an overall positive effect on UTM systems, if these technologies are exploited for this purpose as well as for the benefit of individual drivers. This is not the case at present. It should also be remembered that improved services for private vehicles may promote car travel in the place of public transport as improved comfort and safety as a result of newer vehicle technologies may attract more car drivers, potentially at the expense of public transport. There is therefore also a need for complimentary measures, such as demand management, public transport priorities and increased use of ITS on public transport to improve service quality. This will all be necessary if new technologies are to contribute to the realisation of a sustainable transport system.

\section{Acknowledgement}

This is paper is based on the state-of-the-art review carried out for the SUE-FUTURES project funded by the Engineering and Physical Sciences Research Council (EPSRC). The authors would like to thank EPSRC for sponsoring the project which made this research possible.

\section{References}

[1] Bretherton D., Wood K., Baker K., Radia B.: 'Congestion and Incident Management Using the SCOOT UTC System'. Proc. $10^{\text {th }}$ Int. Conf. Road Transport Information and Control, IEE London, 2000

[2] Morris R., Cherrett T.: 'The use of SCOOT outputs at ROMANSE in Southampton'. Proc. IEEE Intelligent Transportation Systems Conference, Oakland, 2001

[3] Cartwright M.: 'UTMC: A Market Friendly Framework for Traffic Management systems'. Proc. 12th int. Conf. Road Transport Information and Control, IEE London, 2004

[4] Vahidi A., Eskandarian A.: 'Research advances in intelligent collision avoidance and adaptive cruise control', IEEE transactions on intelligent transportation systems, 2003, 4, (3), pp143-153

[5] Mehta V.D., Walker W.E., Marchau-V., Agusdinata D.B.; 'Dealing with uncertainties in implementing intelligent speed adaptation and adaptive cruise control: an adaptive policymaking approach'. Proc. 13th ITS World Congress, London, 2006

[6] Cheese J.J. and Radia B.: 'UTMC Programme Overview: Emerging results, Communications Standards and the Demonstration Projects'. Proc. $10^{\text {th }}$ Int. Conf. Road Transport Information and Control, IEE London, 2000

[7] Hunt P.B., Robertson D.I., Bretherton R.D. and Winton R.I.: 'SCOOT: A Traffic Responsive Method for Co-ordinating Signals'. Transport and Road Research Laboratory Report LR 1014, Crowthrone, UK, 1981

[8] Bowen G.T. and Bretherton R.D.: 'Latest developments in SCOOT - version 3.1'. Proc. 8th Int. Conf. Road Transport Monitoring and Control, IEE London, 1996

[9] Hounsell, N. B. and McLeod, F.N.: 'Automatic Vehicle Location and Bus Priority: The London System'. Proc. 8th World Conf. on Transport Research, Antwerp, 1999.

[10] Leuillette R., Bishton N., Ridley I. and Sharp W.: 'Informing the Traveller and Welcoming the Visitor - The Reading and Stratford-upon-Avon UTMC Demonstrators'. Proc. 12th Int. Conf. Road Transport Information and Control, IEE London, 2004

[11] Commission for Integrated Transport: 'Paying for Road Use. Commission for Integrated Transport Report', 2002, Available from: http://www.cfit.gov.uk/docs/2002/pfru/pfru/pdf/pfru.pdf, accessed January 2009. 
[12] Department for Transport: 'Feasibility Study of Road Pricing in the UK', Department for Transport, 2004, .http://www.dft.gov.uk/stellent/groups/dft roads/documents/page/dft roads 029788.hcs $\underline{\mathrm{p}}$, accessed January 2009

[13] Alger M., Quartier F. and Gerasimon N.: 'Road Traffic Information from GSM Signalling Data- Results and Applications'. Proc. $4^{\text {th }}$ European Congress on Intelligent Transport Systems and services, Budapest, 2004

[14] Gibbard C.: 'The Development of Bus Real-Time Systems in the UK'. Proc. $4^{\text {th }}$ European Congress on Intelligent Transport Systems and services, Budapest, 2004

[15] Siemens: 'Comet: modular traffic management system'. Siemens Traffic Controls, 2007

[16] Bretherton D.; 'SCOOT MC3 and Current Developments'. Proc. TRB $86^{\text {th }}$ Annual Meeting (CD-ROM), Washington, 2007

[17] Hounsell N.B., Shrestha B.P. Head J.R., Palmer S., Bowen T.: 'The Way Ahead for London's Bus Priority at Traffic Signals'. IET Intell. Transp. Syst., 2008, 2, (3), pp.193200.

[18] Böhm M, McDonald M, Piao J.: 'Co-operative Infrastructure to Vehicle Communication to increase Road safety along Motorways', Journal of eurotransport, 2007, 2, pp72-75.

[19] Schmid A, Jeftic Z, and Kompfner P.: 'High level architecture for cooperative vehicle infrastructure systems', Thinking Highways, 2007, 2, (3), pp11-14

[20] Farradyne P.B.: 'VII architecture and functional requirements', Report prepared for the ITS Joint Programme Office, Federal Highway Administration, U.S Department of Transportation, 2005

[21] McEwen, A.: 'Satnav kits become the latest 'must-steal'. Evening News, Edinburgh. Available from: http://edinburghnews.scotsman.com/latestnews/Satnav-kits-becomethe-latest.2826564.jp, Accessed June 2009

[22] Sparmann, J.M.: 'LISB route guidance and information system: first results of the field trial'. Proc. Vehicle Navigation and Information Systems Conference, Toronto, pp 463466, 1989

[23] Eby, D.W. \& Kostyniuk, L.P.: 'An on-the-road comparison of in-vehicle navigation assistance technologies: The FAST-TRAC troika study'. Proc. 4th World Congress on Intelligent Transportation Systems, Berlin (CD-ROM), 1997.

[24] Simmons N., Gates G. and Burr J.: 'Commercial Applications Arising from a Floating Vehicle Data System in Europe'. Proc. 9th World Congress On Intelligent Transport Systems, Chicago, 2002.

[25] Fancher, P.: 'Intelligent cruise control field test', UMTRI Research UMTRI-98-17, 1998.

[26] Venhovens, P., Naab, K., Adiprasito, B.: 'Stop and go cruise control', FISITA World Automotive Congress, Seoul, 2000

[27] Shladover S.E. and Tan S.K.: 'Analysis of Vehicle Positioning Accuracy Requirements for Communication-Based Cooperative Collision Warning'. Journal of Intelligent Transportation Systems, 10(3), pp 131-140, 2006

[28] Bishop R.: 'A survey of intelligent vehicle applications worldwide', Proc. IEEE Intelligent Vehicles Symposium, Michigan, 2000

[29] EDMap Consortium: 'Enhanced digital mapping project - Final Report'. Submitted to the US Department of Transportation. Federal Highway and Administration and National traffic and Safety Administration, 2004. 
[30] Varrhelyi A. and Makinen T.: 'The effects of in car speed limiter: field studies', Transp. Res. Part C, 2001, 9, (3), pp. 191-211

[31] Lind G.: 'Intelligent speed adaptation in Sweden - important evaluation issues in largescale testing'. Proc. 6th World Congress on Intelligent Transport Systems, Toronto, 1999

[32] Hauschild M.: 'Weather and Road Surface Information and Hazard Warnings -- Data Content Acquisition through Advanced Probe Vehicle Systems'. Proc. $12^{\text {th }}$ World Congress on Intelligent Transport Systems, San Francisco, 2005.

[33] Beecroft M., McDonald M., Lyons G., Bell M.: 'FUTURES: Future Urban Technologies Undertaking Research to Enhance Sustainability'. Proc. 13th World Congress on Intelligent Transport Systems and Services, London, 2006

[34] Levinson D.: 'The value of advanced traveler information systems for route choice'. Transportation Research Part C, 11 pp 75-87, 2003.

[35] Breitenberger S., Grueber B., Neuherz M., Kates R.: 'Traffic information potential and necessary penetration rates'. Traffic Engineering and Control, 45(11), pp396-401, 2004

[36] Ortgiese M. and Escher A.: 'Use case and system requirements', Deliverable of GST Enhanced floating car data, 2004 